\title{
Effect of moderate alcohol upon obstructive sleep apnoea
}

\author{
M.F. Scanlan ${ }^{\#}$, T. Roebuck ${ }^{\#}$, P.J. Little ${ }^{\star}$, J.R. Redman ${ }^{+}$, M.T. Naughton ${ }^{\#}$
}

Effect of moderate alcohol upon obstructive sleep apnoea. M.F. Scanlan, T. Roebuck, P.J. Little, J.R. Redman, M.T. Naughton. (C)ERS Journals Ltd 2000.

ABSTRACT: Moderate-to-large quantities of alcohol are known to aggravate severe obstructive sleep apnoea (OSA), however, the reported effects of moderate alcohol consumption upon mild-to-moderate OSA are inconsistent. Given the reported benefits of moderate alcohol consumption on cardiovascular mortality, recommendations regarding the management of patients with OSA are difficult to formulate. The aim of this study was to evaluate the effects of moderate alcohol on sleep and breathing in subjects with mild-to-moderate OSA.

Twenty-one male volunteers, who snored habitually, underwent polysomnography with and without $0.5 \mathrm{~g}$ alcohol $\cdot \mathrm{kg}$ body weight $(\mathrm{BW})^{-1}$ consumed $90 \mathrm{~min}$ prior to sleep time, in random order. The mean blood alcohol concentration (BAC) following alcohol at the time of lights out was $0.07 \mathrm{~g} \cdot \mathrm{dL}^{-1}$.

The distribution amongst the various sleep stages was not significantly altered by alcohol. The mean apnoea/hypopnoea index rose from $7.1 \pm 1.9$ to $9.7 \pm 2.1$ events $^{-1} h^{-1}$ (mean \pm seM, $p=0.017$ ); however, there was no significant change in the minimum arterial oxygen saturation measured by pulse oximetry $S_{\mathrm{p}, \mathrm{O}_{2}}$, apnoea length or snoring intensity. Mean sleep cardiac frequency rose significantly from $53.9 \pm 1.4$ to $59.9 \pm 1.9$ beats min $^{-1}(\mathbf{p}<0.001)$ and overnight urinary noradrenalin increased from $14.9 \pm 2.3$ to $18.8 \pm 2.3 \mathrm{nmol} \cdot \mathrm{mmol}$ creatinine $\mathrm{e}^{-\mathrm{T}}(\mathrm{p}=0.061)$ on the alcohol night compared to the nonalcohol night.

To conclude, modest alcohol consumption, giving a mean blood alcohol concentration of $0.07 \mathrm{~g} \cdot \mathrm{dL}^{-1}$, significantly increases both obstructive sleep apnoea frequency and mean sleep cardiac frequency.

Eur Respir J 2000; 16: 909-913.

The treatment of obstructive sleep apnoea (OSA), a condition commonly associated with cardiovascular disease and autonomic disturbance, usually includes lifestyle modification such as avoidance or minimization of alcohol [1]. However, health practitioners frequently tell patients that alcohol, taken in moderate quantities, has beneficial effects upon cardiovascular mortality $[2,3]$. In particular, published guidelines suggest a "safe upper level" of four standard (10 g alcohol) drinks of alcohol per day in males before the adverse effects of hypertension, heart and liver disease develop [4-7]. For an $80 \mathrm{~kg}$ male, this would equate to $0.5 \mathrm{~g}$ alcohol $\cdot \mathrm{kg}$ body weight $(\mathrm{BW})^{-1}$.

Alcohol, consumed in large quantities $(>1.0 \mathrm{~g}$ alcohol. $\cdot \mathrm{kg} \mathrm{BW}^{-1}$ ), sufficient to increase the blood alcohol concentrations (BAC) to $>0.075 \mathrm{~g} \cdot \mathrm{dL}^{-1}$, increases apnoea frequency, length and associated hypoxaemia in patients with OSA [8-11]. However, the effects of alcohol at lower doses $\left(0.5-1.0 \mathrm{~g}\right.$ alcohol $\left.\cdot \mathrm{kg} \mathrm{BW}^{-1}\right)$ on OSA are less clear. When subjects were given $0.5 \mathrm{~g}$ alcohol $\cdot \mathrm{kg}$ $\mathrm{BW}^{-1}$ (with a corresponding mean BAC of $0.075 \mathrm{~g} \cdot \mathrm{dL}^{-1}$ ), Collop et al. [12] observed a significant rise in the mean apnoea/hypopnoea index (AHI), from 10 to 20 events $\cdot \mathrm{h}^{-1}$. In contrast, BLOCK et al. [13] found no difference in the AHI (2.8 to 3.0 events $\left.\cdot \mathrm{h}^{-1}\right)$ when subjects, with milder OSA, were given $1 \mathrm{~g}$ alcohol $\cdot \mathrm{kg} \mathrm{BW}^{-1}\left(\mathrm{BAC} 0.075 \mathrm{~g} \cdot \mathrm{dL}^{-1}\right)$. Similarly, TESCHLER et al. [14] found no difference in the
\#Dept of Respiratory Medicine and Monash University Medical School, Alfred Hospital, and ${ }^{+}$Dept of Psychology, Monash University, and Baker Medical Research Institute, Prahran, Victoria, Australia.

Correspondence: M.T. Naughton

Dept of Respiratory Medicine

Alfred Hospital

Commercial Road

Prahran

Melbourne

Victoria, 3181

Australia

Fax: 61392763601

Keywords: Alcohol apnoea

sleep

Received: December 231999

Accepted after revision July 182000

This study was supported by a grant from the Alfred Hospital Research Foundation.
AHI (44-51 events $\cdot h^{-1}$ ) when males with severe OSA were given $0.5 \mathrm{~g}$ alcohol. $\mathrm{kg} \mathrm{BW} \mathrm{BW}^{-1}\left(\mathrm{BAC} 0.05 \mathrm{~g} \cdot \mathrm{dL}^{-1}\right)$.

In order to further understand the effects of alcohol on sleep-disordered breathing and associated autonomic disturbance, the authors undertook a randomized controlled study to determine the effects of moderate alcohol consumption on snoring severity, sleep quality, apnoea/ hypopnoea frequency and on the markers of sympathetic activity in male subjects with habitual snoring and various levels of OSA.

\section{Methods}

\section{Subjects}

Male subjects, aged 30-60 yrs, who met the following criteria: habitual snoring, moderate alcohol consumption, absence of any significant medical conditions and free of regular medication, were recruited. Moderate alcohol consumption was defined as $<1 \mathrm{~g}$ alcohol $\cdot \mathrm{kg} \mathrm{BW}^{-1}$ for $\leq 5$ days. week ${ }^{-1}$. Subjects were recruited from advertisements placed around the hospital and from patients referred to the sleep clinic. The Ethics Committee of the Alfred Hospital approved the study and patients provided written informed consent. 


\section{Sleep studies}

Overnight sleep studies were performed in the usual

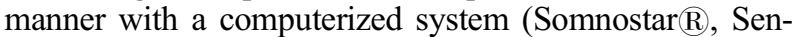
sorMedics Corp, CA, USA), two electroencephalogram (EEG) channels, left and right electrooculograms (EOGs) and submental electromyogram (EMG) for the determination of sleep stages. Sleep stages were manually scored according to standard criteria by an experienced scorer blinded to the patients' details as previously described [15]. Sleep efficiency was defined as total sleep time/time in bed and \% sleep stage as the total time spent in a particular sleep stage/total sleep time. Electrocardiogram (ECG) and cardiac frequency were recorded continuously from precordial lead II; arterial oxygen saturation was measured by an ear pulse oximeter $\left(\mathrm{Sp}, \mathrm{O}_{2}\right)$ (Fastrac, Sensormedics Corp, CA, USA). Chest and abdominal movements were monitored using respiratory effort bands calibrated for phase but not tidal volume (Resp-ez ${ }^{\mathrm{TM}}$, EPM Systems, VA, USA). Oronasal airflow was monitored by thermocouples (ProTech Services, WA, USA). Snoring was measured with an audiometer placed $1 \mathrm{~m}$ above the participants head (Rion NA-24, Rion Tokyo, Japan). Snoring intensity was calculated by: 1) the area under the curve of the sound intensity versus time graph, 2 ) the peak noise in rapid eye movement (REM) and nonREM (NREM) sleep, and 3) the \% sleep time spent with noise $>50 \mathrm{~dB}$. Arousals were defined as episodes lasting $\geq 3 \mathrm{~s}$ in which there was a return of alpha activity associated with increased EMG activity [16].

An obstructive apnoea was defined as an absence of oronasal airflow for $\geq 10 \mathrm{~s}$ despite continued out-of-phase chest and abdominal movements. An obstructive hypopnoea was defined as a reduction in oronasal airflow for $\geq 10$ s associated with a $\geq 2 \%$ fall in $S \mathrm{p}, \mathrm{O}_{2}$ despite continued out-of-phase chest and abdominal movements, increased submental EMG activity, or snoring. Patients with central apnoea were excluded from the study. The AHI was defined as the total number of apnoeas and hypopnoeas divided by the total sleep time, and expressed as the number of events per hour.

\section{Catecholamine measurements}

Urinary noradrenalin (UNA) was measured from urine produced overnight during the period of the sleep study. Urine collection began after subjects had voided prior to retiring to bed $(\sim 22: 00 \mathrm{~h})$ and included all urine passed overnight, including the first morning void upon arising $(\sim 6: 00 \mathrm{~h})$. Urine was collected in acidified containers with $20 \mathrm{~mL}$ of $6 \mathrm{M} \mathrm{HCL}$, and stored at $4^{\circ} \mathrm{C}$ prior to analysis. Noradrenalin was measured by high-performance liquid chromatography (HPLC) with fluorescence detection [17]. To take into account possible differences in renal function, UNA was adjusted for creatinine excretion and expressed as nmol.mmol creatinine ${ }^{-1}$ as previously described [18].

\section{Alcohol measurements}

Blood alcohol levels were estimated from the alcohol concentration in the expired breath using an alcohometer (Lion laboratories, South Wales, UK) [19].

\section{Arterial blood gas measurements}

An arterial blood gas sample was taken from the radial artery using a 25 -gauge needle, and blood gases and $\mathrm{pH}$ levels were determined (ABL 500 Radiometer; Radiometer-Copenhagen, Denmark) immediately before the sleep studies.

\section{Protocol}

Eligible subjects underwent two sleep studies, a week apart, in random order with and without alcohol. Subjects were asked to refrain from alcohol during the day prior to sleep studies. Each subject was breathalysed upon arrival at the sleep centre to ensure no alcohol had been consumed prior to the study.

On the night of each sleep study, a standard hospital meal was provided at 19:30 $\mathrm{h}$ and thereafter sleep monitoring leads were attached between 20:00 and 21:00 h. Between 21:00 and 22:30 h, subjects consumed $0.5 \mathrm{~g} \cdot \mathrm{kg}$ $\mathrm{BW}$ alcohol ${ }^{-1}$ (chilled white wine) or water depending upon randomization.

\section{Statistical analysis}

Data are expressed as mean \pm SEM. A p-value of $<0.05$ was regarded as significant. The Wilcoxon signed-rank test was used to compare the data.

\section{Results}

Twenty-one male subjects undertook the study. The mean age was $43.5 \pm 1.7$ (range 34-59) yrs, body mass index (BMI) $27.8 \pm 0.8$ (range $21-38) \mathrm{kg} \cdot \mathrm{m}^{-2}$ and average alcohol consumption was $13.1 \pm 1.4$ standard drinks. week $^{-1}$.

The mean BAC was $0.07 \pm 0.01 \mathrm{~g} \cdot \mathrm{dL}^{-1}$ following alcohol consumption just prior to lights out. On the alcohol night, compared with the control night, there was a significant reduction in NREM sleep latency $(10 \pm 1$ versus $19 \pm 3 \mathrm{~min}$, $\mathrm{p}<0.01)$ but no statistical difference in REM latency $(125 \pm 10$ versus $110 \pm 13 \mathrm{~min}, \mathrm{p}=0.303)$ (table 1$)$. The distribution of sleep amongst the various sleep stages was unaffected by alcohol (table 1).

Table 1. - Sleep architecture and latency on control and alcohol nights

\begin{tabular}{lcc}
\hline & Control & Alcohol \\
\hline Time in bed min & $464 \pm 6$ & $452 \pm 4$ \\
Total sleep time min & $400 \pm 11$ & $399 \pm 8$ \\
Sleep period time min & $447 \pm 7$ & $441 \pm 5$ \\
Sleep efficiency & $87 \pm 2$ & $88 \pm 1$ \\
Wake \% SPT & $11 \pm 2$ & $10 \pm 1$ \\
Stage 1\&2 \% SPT & $58 \pm 2$ & $60 \pm 2$ \\
Slow wave sleep \% SPT & $13 \pm 1$ & $13 \pm 1$ \\
REM \% SPT & $19 \pm 1$ & $18 \pm 1$ \\
NREM sleep latency min & $19 \pm 3$ & $10 \pm 1 * *$ \\
REM sleep latency min & $110 \pm 13$ & $125 \pm 10$ \\
Arousals events $\cdot \mathrm{h}^{-1}$ & $17 \pm 2$ & $19 \pm 3$ \\
\hline
\end{tabular}

Data are presented as mean \pm SEM. $* *$ : $\mathrm{p}<0.01$ versus control. $\%$ SPT: per cent sleep period time; REM: rapid eye movement; NREM: non-REM. 
Table 2. - Effect of alcohol upon obstructive sleep apnoea, cardiac frequency and urinary noradrenalin

\begin{tabular}{|c|c|c|}
\hline & Control & Alcohol \\
\hline AHI events $\cdot h^{-1}$ & $7.1 \pm 1.9$ & $9.7 \pm 2.1^{\#}$ \\
\hline Apnoea length (NREM) & $16.0 \pm 0.7$ & $17.2 \pm 1.2$ \\
\hline Apnoea length (REM) & $18.9 \pm 1.2$ & $18.9 \pm 1.5$ \\
\hline \multicolumn{3}{|l|}{ Snoring } \\
\hline AUC ÄU & $184 \pm 8$ & $198 \pm 9$ \\
\hline Peak intensity (NREM) dB & $52.5 \pm 2.5$ & $49.7 \pm 2.2$ \\
\hline Peak intensity (REM) dB & $47.7 \pm 2.4$ & $46.4 \pm 1.8$ \\
\hline$\%$ TST $>50 \mathrm{~dB}$ & $40 \pm 18$ & $39 \pm 18$ \\
\hline Mean $S \mathrm{p}, \mathrm{O}_{2} \%$ & $95.9 \pm 0.4$ & $95.3 \pm 0.4$ \\
\hline Minimum $S \mathrm{p}, \mathrm{O}_{2} \%$ & $86.6 \pm 1.9$ & $85.8 \pm 1.6$ \\
\hline SPT with $S \mathrm{p}, \mathrm{O}_{2}<90 \%(\%)$ & $1.5 \pm 0.8$ & $3.6 \pm 1.9$ \\
\hline UNE nmol-mmol creatinine ${ }^{-1}$ & $14.9 \pm 2.3$ & $18.8 \pm 2.3^{+}$ \\
\hline Urine volume $\mathrm{mL}$ & $730 \pm 106$ & $900 \pm 62$ \\
\hline Cardiac frequency beats $\mathrm{min}^{-1}$ & $53.9 \pm 1.4$ & $59.9 \pm 1.9 * *$ \\
\hline
\end{tabular}

Data are presented as mean \pm SEM. AHI: apnoea/hypopnea index; REM: rapid eye movement; NREM: non-REM; AUC: area under the curve; AU: arbitrary units; TST: total sleep time; $S \mathrm{p}, \mathrm{O}_{2}$ : arterial oxygen saturation measured by pulse oximetry; SPT: sleep period time; UNA: urinary noradrenalin. ${ }^{\#}: \mathrm{p}<0.025$; ${ }^{+}: \mathrm{p}=0.061 ; * *: \mathrm{p}<0.01$.

On the alcohol night, compared with the control night, there was a significant increase in the total AHI $(9.7 \pm 2.1$ versus $7.1 \pm 1.9 \mathrm{~h}, \mathrm{p}=0.017$ ) (table 2 and fig. 1 ). There was no significant difference in the increase (alcohol-control) in the AHI for those subjects randomized to receive alcohol on the first night $(\mathrm{n}=10)$ compared to the control subjects $(\mathrm{n}=11$ ), (change in AHI $2.4 \pm 2.9$ versus $2.1 \pm 0.8$ events $\cdot \mathrm{h}^{-1}$, respectively, $\left.\mathrm{p}=0.561\right)$, suggesting that there was no order effect. There was also no significant correlation between the increase in AHI and baseline AHI $(\mathrm{r}=-0.225, \mathrm{p}=0.465)$, body mass index $(\mathrm{r}=0.191, \mathrm{p}=0.407)$ or age $(\mathrm{r}=0.052, \mathrm{p}=0.853)$.

Of the 21 subjects, the AHI rose in 16, fell in four and was unchanged in one. There was no significant difference in BAC $\left(0.07 \pm 0.03\right.$ versus $\left.0.07 \pm 0.01 \mathrm{~g} \cdot \mathrm{dL}^{-1}, \mathrm{p}=\mathrm{Ns}\right)$, age (44.2 \pm 2.0 versus $41.0 \pm 4.4, \mathrm{p}=\mathrm{NS})$, BMI (27.6 \pm 1.1 versus $28.6 \pm 1.0, \mathrm{p}=\mathrm{NS})$ or prior average weekly alcohol consumption $\left(13.1 \pm 1.6\right.$ versus $14.3 \pm 3.8$ drinks $\cdot$ week $\left.^{-1}, \mathrm{p}=\mathrm{NS}\right)$ between those subjects who showed an increase in the AHI

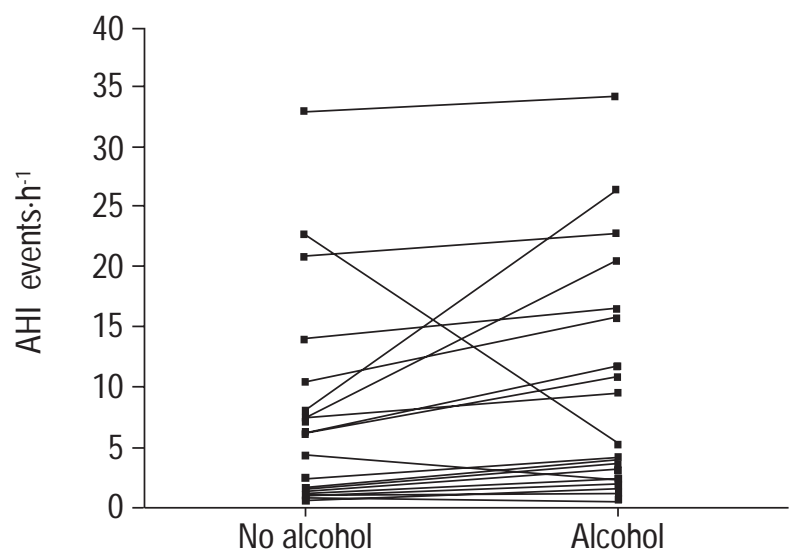

Fig. 1. - Individual apnoea/hypopnoea indices (AHI) of all subjects on control nights and alcohol nights. The mean AHI was significantly greater on alcohol $\left(9.7 \pm 2.1\right.$ events $\left.\cdot h^{-1}\right)$ than on control nights $(7.1 \pm 1.9$ events $\left.\cdot \mathrm{h}^{-1}, \mathrm{p}=0.017\right)$.

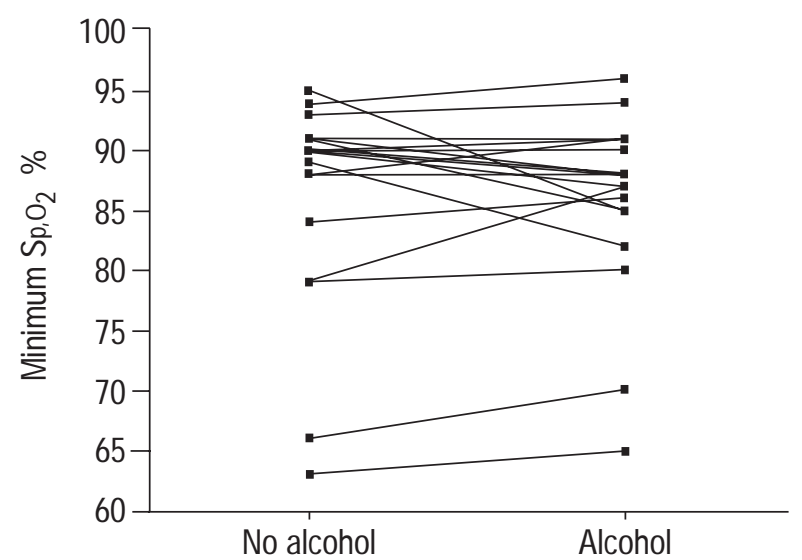

Fig. 2. - Individual minimum arterial oxygen saturation measured by pulse oximetry $\left(\mathrm{Sp}, \mathrm{O}_{2}\right)$ values for all subjects on control and alcohol nights. There was no significant difference in minimum $S \mathrm{p}, \mathrm{O}_{2}$ between alcohol $(85.8 \pm 1.6 \%)$ and control nights $(86.6 \pm 1.9 \%, \mathrm{p}=\mathrm{NS})$.

with alcohol compared to those who showed a decrease. However, in all subjects with an AHI $<5$ events $\cdot \mathrm{h}^{-1}$ on the control night $(\mathrm{n}=11)$, the AHI remained $<5$ events $\cdot \mathrm{h}^{-1}$ on the alcohol night.

There was no significant change in the levels of apnoearelated hypoxaemia (fig. 2) or apnoea length during NREM or REM sleep with alcohol (table 2). Moreover, the sound intensity of snoring did not change significantly on the alcohol night compared with the control night (table 2).

There was a significant rise in the mean sleep cardiac frequency on the alcohol night compared with the control night $\left(59.9 \pm 1.9\right.$ versus $53.9 \pm 1.4$ beats. $\left.\mathrm{min}^{-1}, \mathrm{p}<0.01\right)$ (fig. 3 ), a rise that was associated with a trend towards an increase in UNA ( $18.8 \pm 2.3$ versus $14.9 \pm 2.3 \mathrm{nmol} \cdot \mathrm{mmol}$ creatinine $\left.^{-1}, \mathrm{p}=0.061\right)$. Arterial blood gases, taken in a subgroup of six subjects, revealed a significant shift in $\mathrm{pH}$ towards acidaemia $(7.37 \pm 0.01$ versus $7.41 \pm 0.01, \mathrm{p}<0.05)$ and a trend towards hypocapnia $(41.3 \pm 0.5$ versus $44.3 \pm$ $0.6 \mathrm{kPa}, \mathrm{p}=0.061)$ without a change in oxygen tension in arterial blood $\left(\mathrm{Pa}_{\mathrm{a}} \mathrm{O}_{2}\right)(88.3 \pm 2.6$ versus $87.7 \pm 3.5 \mathrm{kPa}$ $\mathrm{p}=\mathrm{NS})$ or $\mathrm{Sa}, \mathrm{O}_{2}(98.0 \pm 0.6$ versus $97.7 \pm 0.5 \%, \mathrm{p}=\mathrm{Ns})$ with alcohol, compared with the control night, indicating a mild metabolic acidosis induced by alcohol.

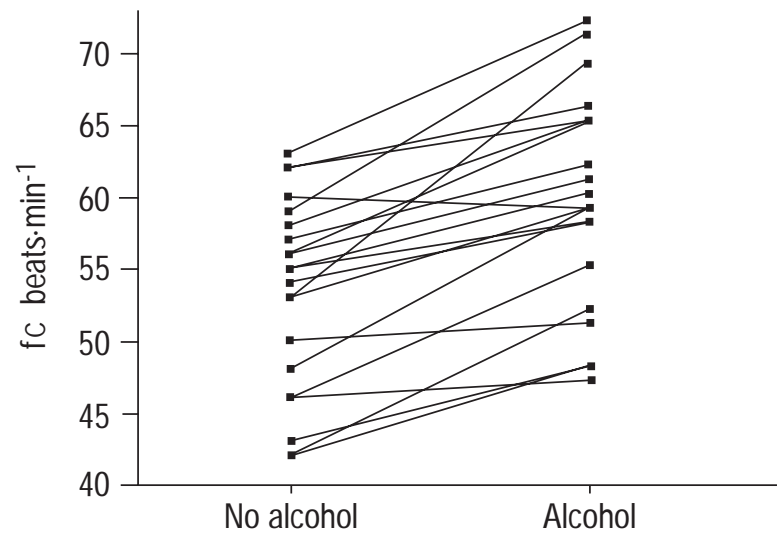

Fig. 3. - Individual mean sleep cardiac frequency $(f \mathrm{C})$ data of all subjects on control and alcohol nights. The mean $f \mathrm{C}$ was significantly greater following alcohol $\left(59.9 \pm 1.9\right.$ beats $\left.\cdot \mathrm{min}^{-1}\right)$ compared with control night $\left(53.9 \pm 1.4\right.$ beats $\left.\cdot \mathrm{min}^{-1}, \mathrm{p}<0.01\right)$. 
On the control nights, the UNA correlated significantly with minimum $S \mathrm{p}, \mathrm{O}_{2}(\mathrm{r}=-0.600, \mathrm{p}<0.001)$ and mean $S \mathrm{p}, \mathrm{O}_{2}$ $(\mathrm{r}=-0.435, \mathrm{p}=0.045)$, and showed a trend towards significance with total sleep time spent with $\mathrm{Sp}_{\mathrm{p}} \mathrm{O}_{2}<90 \%$ $(\mathrm{r}=0.417, \mathrm{p}=0.075)$ but not AHI $(\mathrm{r}=0.382, \mathrm{p}=0.106)$ or the arousal index $(r=0.182, p=0.457)$. Mean sleep cardiac frequency also correlated with the minimum $S \mathrm{p}, \mathrm{O}_{2}$ ( $\mathrm{r}=-0.455$, $\mathrm{p}=0.039$ ), and showed significance with total sleep time spent with $S \mathrm{p}, \mathrm{O}_{2}<90 \%(\mathrm{r}=-0.403, \mathrm{p}=0.070)$, but did not correlate with the AHI $(\mathrm{r}=-306, \mathrm{p}=0.177)$ or arousal index $(r=0.287, p=0.207)$.

\section{Discussion}

The major finding of this study was that moderate alcohol intake $\left(0.5 \mathrm{~g}\right.$ alcohol.kg $\left.\mathrm{BW}^{-1}\right)$, sufficient to increase the BAC to $0.07 \mathrm{~g} \cdot \mathrm{dL}^{-1}$ resulted in a small but statistically significant rise in the frequency of obstructive apnoeas and hypopnoeas, without prolonging the apnoea length or worsening hypoxaemia. The effect of alcohol upon the AHI could not be explained by age or the body mass index. Moreover, mean sleep cardiac frequency increased significantly with alcohol. These results would suggest that the severity of obstructive sleep apnoea in subjects with habitual snoring may increase with moderate alcohol consumption prior to sleep time.

Alcohol minimization or abstinence is frequently recommended in the management of patients with obstructive sleep apnoea [1]. Proposed mechanisms for the adverse effects of alcohol upon OSA include selective reduction in genioglossus and hypoglossal motor nerve activity [20-23], increased nasal mucosa oedema and thereby increased resistance [21], a reduction in arousal response $[8-10]$ and a reduced haemoglobin affinity for oxygen [23]. In addition, considerable evidence exists that alcohol fragments sleep, independent of apnoea status [24], which may further aggravate OSA [25]. Moreover, alcohol may have a direct toxic effect upon the myocardium [26].

Alcohol given in large quantities significantly worsens OSA $[8,9]$. At doses of $0.9-3.0 \mathrm{~g}$ alcohol. $\mathrm{kg} \mathrm{BW}^{-1}$, AHI and apnoea length increased significantly resulting in greater hypoxaemia in seven males with severe OSA [8]. Similarly, TAASAN et al. [9] described an increase in OSA severity in subjects, asymptomatic of OSA, given $1 \mathrm{~g}$ alcohol $\cdot \mathrm{kg} \mathrm{BW}^{-1}$. Moreover, BLock et al. [13] reported that apnoea was worsened by $1 \mathrm{~g}$ alcohol. $\mathrm{kg} \mathrm{BW}^{-1}$ in males (but not in females) with mild sleep apnoea.

However, when alcohol is given in moderate doses $(0.5-$ $1.0 \mathrm{~g} \cdot \mathrm{kg} \mathrm{BW}^{-1}$ ), the effects upon apnoea severity are less clear. Some authors report an increase [9, 12, 27] and others no effect $[13,14]$ upon severity of OSA. BERRY et al. [10] reported $0.5 \mathrm{~g}$ alcohol $\cdot \mathrm{kg} \mathrm{BW}^{-1}$ did not alter respiration during sleep. TESCHLER et al. [14] suggested similar doses did not alter pressure requirements to maintain ventilation during sleep in patients with severe OSA.

Conversely, Collop [12] and Scrima et al. [27] have shown that doses of $0.5 \mathrm{~g}$ alcohol. $\mathrm{kg} \mathrm{BW}^{-1}$ increased the AHI from 9 to 20 events $\cdot h^{-1}[12]$ and the $2 \%$ dips in $S \mathrm{p}, \mathrm{O}_{2}$ from 134 to 210 per night [27]. The findings of the present study support the findings of CoLlop [12] and SCRIMA et al. [17] that alcohol does increase the frequency of respiratory events even in the mild group of subjects and in the absence of increased snoring severity.

Findings of interest in this study were that moderate alcohol consumption had no significant effect on the mean apnoea length or arousal frequency. This observation could be explained by a greater depressant effect of alcohol upon upper airway muscle activity than on arousability. This would be consistent with previous data presented by BERRY et al. [10] who reported an increase in upper airway resistance without a significant change in apnoea length in subjects given alcohol.

Snoring intensity did not significantly change with alcohol consumption in the subjects studied. Although snoring is a hallmark symptom of OSA, it is rarely measured objectively, and there is no standard method to do so. In this study, snoring intensity was objectively measured with an audiometer placed $1 \mathrm{~m}$ from the mouth, a technique similar to that used by previous groups [28, 29]. Analysis was performed using the maximum for NREM and REM stages of sleep, with the area under the curve and the $\%$ sleep time $>50 \mathrm{~dB}$; therefore, the recordings are believed to be accurate.

Another interesting finding in this study was that there was a substantial rise in mean sleep cardiac frequency with alcohol, from $\sim 54$ to $\sim 60 \mathrm{bpm}$, for which several possibilities exist. Firstly, it is possible that the rise was due to the elevation in AHI. However, OSA is usually associated with bradycardia during the apnoea and tachycardia at the terminating arousal. The net gain is usually no significant change in mean cardiac frequency. Moreover, the rise in cardiac frequency was observed in 20 of the 21 subjects studied, and even occurred in those five subjects who did not display a rise in AHI with alcohol. Therefore, the authors believe that the rise in cardiac frequency cannot simply be explained by an increase in OSA severity. Alternatively, the relative tachycardia may have been a response to peripheral systemic vasodilation, an acute effect which occurs with alcohol in subjects with intact baroreceptor function [30, 31]. This may also have contributed to a rise in the overnight urinary excretion of noradrenalin, as observed in this study. Alternatively, alcohol may have a direct sympathetic nervous system excitatory effect. Increased skeletal muscle sympathetic nerve activity, blood pressure and cardiac frequency were observed in awake normal subjects given $1 \mathrm{~g}$ alcohol $\cdot \mathrm{kg}$ $\mathrm{BW}^{-1}$ suggesting that alcohol has a direct sympathoneural stimulatory function [30]. The arterial blood gas measurements that were observed suggested an alcohol-induced trend towards metabolic acidosis and hypocapnia, in the absence of hypoxaemia, which may reflect a manifestation of sympathetic stimulation.

To conclude, the effects of $0.5 \mathrm{~g}$ alcohol $\cdot \mathrm{kg}$ body weight ${ }^{-1}$, a level regarded as the safe upper limit by health authorities, on sleep apnoea in otherwise healthy habitual snorers with mild-to-moderate obstructive sleep apnoea were studied. A small but statistically significant rise in sleep apnoea severity, cardiac frequency and a trend towards an increase in overnight urinary noradrenalin was observed. Given the enormity of public health issues related to obstructive sleep apnoea, public health authorities, who provide statements regarding the safe levels of alcohol consumption, should also be reminded of the potential adverse effects of alcohol upon apnoea severity. 
Acknowledgements. The authors would like to thank the participating subjects and the staff of the sleep laboratory. M.F. Scanlan was a recipient of the Dept of Respiratory Medicine Research Scholarship.

\section{References}

1. Strollo PJ, Rogers RM. Obstructive sleep apnea. $N$ Engl $J$ Med 1996; 334: 99-104.

2. Thun MJ, Peto R, Lopez AD, et al. Alcohol consumption and mortality among middle-aged and elderly U.S. adults. N Engl J Med 1997; 337: 1705-1714.

3. Doll R, Peto R, Hall E, Wheatley K, Gray R. Mortality in relation to consumption of alcohol: 13 years' observation on male doctors. BMJ 1994; 309: 911-918.

4. Holman CDJ, English DR, Milne E, Winter MG. Metaanalysis of alcohol and all-cause mortality: a validation of NHMRC recommendations. Med J Aust 1996; 164: 141145.

5. McElduff P, Dobson AJ. How much alcohol and how often? Population based case-control study of alcohol consumption and risk of a major coronary event. $B M J$ 1997; 314: 1159-1164.

6. Australian National Health and Medical Research Council. Is there a Safe Level of Daily Consumption of Alcohol for Men and Women? Recommendations Regarding Responsible Drinking Behaviour. Canberra, Australian Government Printing Service, 1992.

7. National Institute on Alcohol Abuse and Alcoholism. The Physicians Guide to Helping Patients with Alcohol Problems. NIH publication No. 95-3769. Washington, DC, Government Printing Office, 1995.

8. Issa FQ, Sullivan CE. Alcohol, snoring and sleep apnoea. J Neurol Neurosurg Psychiatry 1982; 45: 353-359.

9. Taasan VC, Block AJ, Boysen PG, Wynne JW. Alcohol increases sleep apnea and oxygen desaturation in asymptomatic men. Am J Med 1981; 71: 240-245.

10. Berry RB, Bonnett MH, Light RW. Effect of alcohol on the arousal response to airway occlusion during sleep. $\mathrm{Am}$ Rev Respir Dis 1992; 145: 445-452.

11. Berry RB, Desa MM, Light RW. Effect of ethanol on efficacy of nCPAP as a treatment for OSA. Chest 1991; 99: 339-343.

12. Collop NA. Medroxyprogesterone acetate and ethanolinduced exacerbation of obstructive sleep apnea. Chest 1994; 106: 792-799.

13. Block AJ, Hellard DW, Slayton PC. Effect of alcohol on breathing and oxygenation during sleep. Analysis on the influence of age and sex. Am J Med 1986; 80: 595-600.

14. Teschler H, Berthon-Jones M, Wessenddorf T, Meyer H-J, Konietzko N. Influence of moderate alcohol consumption on obstructive sleep apnoea with and without Autoset nasal CPAP therapy. Eur Respir J 1996; 9: 2371-2377.

15. Rechtschaffen A, Kales A. A manual of standardised terminology, techniques and scoring system for sleep stages of human subjects. Publication 204. Washington, DC: National Institutes of Health, 1968.
16. Tsai WH, Flemons WW, Whitelaw WA, Remmers JE. A comparison of apnea-hypopnea indices derived from different definitions of hypopnoea. Am J Respir Crit Care Med 1999; 159: 43-48.

17. Jackson GP. Differential assay for urinary catecholamines by use of liquid chromatography with fluorescence detection. Clin Chem 1981; 27: 1202-1204.

18. Naughton MT, Benard DC, Liu PP, Rutherford R, Rankin F, Bradley TD. Effects of nasal CPAP on sympathetic activity in patients with heart failure and central apnea. Am J Respir Crit Care Med 1995; 152: 473-479.

19. Jones AW. Electrochemical measurement of breathalcohol concentration: precision and accuracy in relation to blood levels. Clin Chim Acta 1985; 146: 175-183.

20. Krol RC, Knuth SL, Bartlett D. Selective reduction of genioglossal muscle activity by alcohol in normal human subjects. Am Rev Respir Dis 1984; 129: 247-250.

21. Robinson RW, White DP, Zwillich CW. Moderate alcohol ingestion increases upper airway resistance in normal subjects. Am Rev Respir Dis 1985; 132: 1238-1241.

22. Bonora M, Shields GI, Knuth SL, Bartlett D Jr, St John WM. Selective depression by ethanol of upper airway respiratory motor activity in cats. Am Rev Respir Dis 1984; 130: 156-161.

23. St John WM, Bartlett D, Knuth KV, Knuth SL, Daubenspeck JA. Differential depression of hypoglossal nerve activity by alcohol. Protection by pretreatment with medroxyprogesterone acetate. Am Rev Respir Dis 1986; 133: $46-48$

24. Landolt HP, Roth C, Dijk DJ, Borbely AA. Lateafternoon ethanol intake affects nocturnal sleep and the sleep EEG in middle-aged men. J Clin Psychopharmacol 1996; 16: 428-436.

25. Leiter JC, Knuth SL, Bartlett DJ. The effect of sleep deprivation on activity of the genioglossus muscle. $\mathrm{Am}$ Rev Respir Dis 1985; 132: 1242-1245.

26. Vikhert AM, Tsiplenkova VG, Cherpachenko NM. Alcoholic cardiomyopathy and sudden cardiac death. $J$ Am Coll Cardiol 1986; 8: 3A-11A.

27. Scrima L, Broudy M, Nay KN, Cohn MA. Increased severity of obstructive sleep apnoea after bedtime alcohol ingestion: diagnostic potential and proposed mechanism of action. Sleep 1982; 5: 318-328.

28. O'Sullivan RA, Hillman DR, Mateljan R, Pantin C, Finucane KE. Mandibular advancement splint: an appliance to treat snoring and obstructive sleep apnea. Am J Respir Crit Care Med 1985; 151: 194-198.

29. Miljeteig H, Mateika S, Haight JS, Cole P, Hoffstein V. Subjective and objective assessment of uvulopalatoplasty for treatment of snoring and obstructive sleep apnea. Am J Respir Crit Care Med 1994; 50: 1286-1290.

30. van de Borne P, Mark AL, Montano N, Mion D, Somers VK. Effects of alcohol on sympathetic activity, hemodynamics and chemoreflex sensitivity. Hypertension 1997; 29: 1278-1283.

31. Abe H, Kawano Y, Kojima S, et al. Biphasic effects of repeated alcohol intake on 24-hour blood pressure in hypertensive patients. Circulation 1994; 89: 2626-2633. 